\title{
NARRATIVAS DE ESTUDANTES DE COMUNIDADES TRADICIONAIS COMO POSSIBILIDADES PARA O DIÁLOGO INTERCULTURAL NO ENSINO DE CIÊNCIAS
}

\author{
Geilsa Costa Santos Baptista ${ }^{1}$ \\ Dirlane Gomes e Silva² \\ Jairo Robles-Piñeros ${ }^{3}$
}

\begin{abstract}
RESUMO:
Apresentamos os resultados de uma pesquisa qualitativa que teve por objetivo identificar quais são as possibilidades de diálogo intercultural na educação científica em biologia a partir de narrativas criadas em linguagem verbal e não verbal por estudantes pertencentes às comunidades tradicionais. 0 estudo teve natureza qualitativa, com análise de conteúdo das narrativas de 35 estudantes agricultores do nível médio em uma escola pública do município de Feira de Santana, Bahia. As análises dos conteúdos dessas narrativas indicam possibilidades de diálogos entre os conhecimentos tradicionais agrícolas e os científicos, com os seguintes conteúdos: interações dos seres humanos com os demais seres vivos; relações ecológicas; aspectos morfológicos dos vegetais; insetos de importância agrícola; o uso de agrotóxicos; saúde dos agricultores; e bioacumulação. Conclui-se que é importante a realização de atividades de ensino envolvendo narrativas dos estudantes, pois facilita a exposição de conhecimentos, a prática pedagógica dialógica e a formação docente neste sentido.
\end{abstract}

Palavras-chave: Comunidades tradicionais. Narrativas. Diálogo intercultural. Ensino de ciências.

\section{NARRATIVES FROM TRADITIONAL COMMUNITIES STUDENTS}

\section{AS POSSIBILITY TO INTERCULTURAL DIALOGUE IN SCIENCE TEACHING}

\begin{abstract}
:
We present the results of a qualitative research that aimed to identify the possibilities of intercultural dialogue into scientific education in biology, starting from narratives created in verbal and non-verbal language student's bellowing to traditional communities. This study had a qualitative nature, with content analysis of narratives from 35 farmer students of middle school of a public-school form Feira de Santana, Bahia. The analysis of those narratives shows the possibility of a dialogue between agricultural traditional knowledge and the scientific knowledge onto the next contents: Interactions between human beings and other organisms; ecological relationships; morphological aspects of plants; agricultural importance insects; use of agrotoxic, and farmer health and biomagnification. In conclusion, it's important to lead teaching activities involving student's narratives, due to it improve the knowledge exposition, the dialogical pedagogical practice and the teacher training in this sense. Keywords: Intercultural dialogue. Narratives. Science teaching. Traditional communities.
\end{abstract}

RECEBIDO EM: 30/3/2018

ACEITO EM: 8/5/2018

\footnotetext{
${ }^{1}$ Graduação em Licenciatura em Ciências Biológicas pela Universidade Estadual de Feira de Santana (1995). Especialização em Saúde Aplicada ao Ensino de Biologia (2000), Mestrado em Ensino, Filosofia e História das Ciências (2007) e Doutorado em Ensino, Filosofia e História das Ciências (2012) pela Universidade Federal da Bahia. Participa como membro da Associação Brasileira de Pesquisa em Educação em Ciências (Abrapec) e da Sociedade Brasileira de Etnobiologia e Etnoecologia (SBBE). Professora titular no Departamento de Educação da Universidade Estadual de Feira de Santana-BA e no Programa de Pós-Graduação em Ensino, Filosofia e História das Ciências (Ufba-Uefs). Fundadora e coordenadora do Grupo de Investigações em Etnobiologia e Ensino de Ciências da Universidade Estadual de Feira de Santana, Bahia (Gieec-Uefs). http://lattes.cnpq.br/7440021393447374. Orcid: https://orcid.org/0000-0002-5871-0115. geilsabaptista@gmail.com

${ }^{2}$ Licenciatura em Ciências Biológicas pela Universidade Estadual de Feira de Santana - Uefs (1994). Especialização em Sistemática de Angiospermas com ênfase na Flora do Nordeste (1999) e Mestrado em Botânica (2002) pela Uefs. Doutoranda no Programa de Pós-Graduação em Ensino, Filosofia e História das Ciências (PPGEFHC, Ufba-Uefs). Professora da Rede de Ensino Básico do Estado da Bahia desde 2002. http:// lattes.cnpq.br/9247107454716036. Orcid: http://orcid.org/0000-0002-8894-9063. dirlanegs@gmail.com

${ }^{3}$ Graduação em Licenciatura em Biologia - Universidad Pedagógica Nacional (2012). Mestrado em Ensino, Filosofia e História das Ciências - Ufba-Uefs (2016). Doutorando do Programa de Pós-Graduação em Ensino, Filosofia e História das Ciências Ufba-Uefs e do Doutorado Interinstitucional em Educação (UDFJC-Colômbia). Membro coordenador do grupo de pesquisa Grupo de Investigações em Etnobiologia e Ensino de Ciências (Ufba-Uefs). Pesquisador e orientador do Grupo de Estudos em Ecologia, Etologia, Educação e Conservação (Gecos) da Universidad Pedagógica y Tecnológica de Colômbia (UPTC). http://lattes.cnpq.br/1434793958389197. http://orcid.org/0000-0002-84033066. jairohxcbogota@gmail.com
} 
Dada a realidade de escolas cada vez mais multiculturais que atendem estudantes pertencentes às diversas culturas, torna-se necessário que os professores busquem abordagens comunicativas dialógicas no ensino das ciências; diálogos que sejam interculturais entre a cultura da ciência que está sendo ensinada e as culturas dos estudantes. O diálogo no ensino de ciências é a relação de comunicação entre professores e estudantes e entre estudantes sobre um determinado tema que é objeto de ensino, com exploração de significados culturais (BAPTISTA, 2010), podendo envolver argumentação no sentido de exposição das justificações a partir dos dados em que se baseiam (OSBORNE et al., 2001).

Para Baptista (2012), diálogos interculturais são importantes porque permitem o respeito à diversidade cultural e a aproximação dos estudantes com a cultura da ciência e a sua linguagem, podendo contribuir para que os sujeitos percebam que entre os conhecimentos científicos e os seus conhecimentos podem existir inúmeras relações, sejam elas de semelhanças e/ou de diferenças. Permitem, ainda, o desenvolvimento intelectual, por contribuir para que os estudantes ampliem seus conhecimentos prévios com conhecimentos científicos e aumentem as suas possibilidades de participação e tomadas de decisão nas sociedades científica e tecnologicamente influenciadas, ou mesmo fora delas, como exemplo, nas comunidades tradicionais. As comunidades tradicionais são grupos diferenciados culturalmente, que ocupam e usam territórios e recursos naturais como condição de sobrevivência (GHEDINI, 2017). Os conhecimentos tradicionais são produtos das comunidades tradicionais e podem ser definidos como o saber e o saber fazer a respeito do mundo natural e sobrenatural, sendo transmitidos de geração a geração em processos educativos cotidianos, frequentemente por meio da oralidade (DIEGUES; ARRUDA, 2001).

Para que o diálogo aconteça é preciso que os professores investiguem os conhecimentos prévios dos estudantes (BAPTISTA, 2010) e explorem os diferentes tipos de linguagens que se fazem presentes nas salas de aula (MORTIMER, 1996). Isto porque, concordando com Vygotsky (1991), é pela linguagem que o homem expressa seus pensamentos, que são direcionados por sua visão de mundo. Cabe destacar que a linguagem pode ser verbal e não verbal. A linguagem verbal utiliza as palavras em formato oral ou escrito. Já a linguagem não verbal faz uso das imagens, desenhos, signos, expressões corporais, entre outros (CAPPELLE; MUNFORD, 2015). Nas salas de aula frequentemente a atenção por parte dos professores é dada à linguagem verbal, especificamente na escrita posta nas denominadas avaliações da aprendizagem ou provas, quando os questionamentos objetivam respostas eminentemente científicas por parte dos estudantes, por o ensino ter por meta a mudança conceitual, isto é, a substituição dos conceitos prévios por conceitos científicos (POSNER et al., 1982).

Essa atenção única às respostas científicas, sem a busca de compreensão de como elas se conectam com os universos culturais dos estudantes, pode trazer consequências negativas para o ensino e para a aprendizagem, especialmente nos contextos das escolas localizadas nas comunidades tradicionais, ou que atendam estudantes delas provenientes, as quais tem seus modos particulares de vivências e conhecimentos da natureza; para o ensino, porque reforça a prática pedagógica pautada na mudança conceitual, que é transmissiva e visa à substituição dos conhecimentos dos estudantes por conhe- 
cimentos científicos; para a aprendizagem, porque os estudantes se sentirão forçados à anulação dos seus saberes e à memorização de conteúdos desprovidos de significados para as suas realidades.

No presente artigo - entendendo a importância do diálogo intercultural para o ensino de ciências, bem como a necessidade de que os professores investiguem e compreendam os saberes culturais dos estudantes e explorem os diferentes tipos de linguagens para que isto ocorra - apresentamos e discutimos os resultados de uma pesquisa qualitativa que teve por objetivo geral identificar quais são as possibilidades de diálogo intercultural na educação científica em biologia a partir de narrativas criadas em linguagem verbal e não verbal por estudantes pertencentes às comunidades tradicionais; particularmente, narrativas de estudantes agricultores que frequentam uma escola pública no Estado da Bahia (Nordeste do Brasil). Também é nosso objetivo que os dados aqui apresentados incentivem professores e pesquisadores da área de ensino de ciências a novas experiências didáticas e pesquisas que envolvam diferentes linguagens para o diálogo intercultural como uma forma de valorização das identidades culturais e ampliação das ideias dos estudantes com ideias científicas.

O termo narrativa vem do verbo narrar, que tem origem no verbo latino narro, que significa contar, expor, fazer saber uma história em detalhe. Para Connelly e Clandinin (1990), uma narrativa pode revelar as diferentes maneiras como os seres humanos experienciam o mundo. Carter (1993) acrescenta que uma narrativa constitui uma apresentação simbólica e sequencial de acontecimentos ligados por um determinado assunto e relacionados pelo tempo. Assim, em diversas narrativas é possível encontrar diferentes compreensões do mundo natural, porque cada cultura percebe a sua realidade cotidiana, e dar-Ihe sentido de um modo particular.

\section{METODOLOGIA}

\section{Caracterização dos Sujeitos e Abordagem do Estudo}

A pesquisa, de natureza qualitativa (BOGDAN; BIKLEN, 1994), foi desenvolvida em 2009 num colégio público estadual localizado no centro de Feira de Santana, Bahia. Tra-

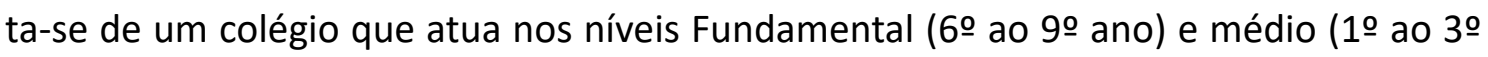
ano), nos turnos matutino e vespertino, e Educação de Jovens e Adultos, no noturno, tendo em média 1.200 estudantes matriculados por ano. Não revelaremos o nome do colégio e nem dos estudantes, posto que no Termo de Consentimento Livre e Esclarecido (TCLE), utilizado na pesquisa, foi garantido sigilo dos nomes dos sujeitos participantes e do estabelecimento de ensino. A legislação utilizada foi aquela voltada para as pesquisas envolvendo seres humanos no Brasil na época em que o estudo foi desenvolvido, isto é, Resolução 196/96 do Conselho Nacional de Saúde (BRASIL, 2003).

Participaram 35 estudantes, entre agricultores e não agricultores, dos gêneros masculino e feminino, com idades variando entre 16 e 21 anos e que frequentavam aulas de biologia para o Nível Médio do colégio sob estudo. Segundo informações desses 35 estudantes, 20 são agricultores e/ou filhos de agricultores, sendo eles provenientes do distrito de João Durval Carneiro (antiga Ipuaçu). Os demais são moradores da Rua Nova, um bairro de Feira de Santana, localizado das imediações do colégio participante. 
Segundo dados obtidos junto a direção do colégio onde nosso estudo aconteceu, o distrito João Durval Carneiro pertence a Feira de Santana, localizando-se a $13 \mathrm{~km}$ ao seu Oeste. A agricultura é a principal fonte de renda dos seus habitantes - cerca de 1.500 pessoas -, especialmente o plantio de milho, feijão e mandioca.

A professora que conduziu as atividades didáticas (segunda autora deste artigo) tinha, em 2009, 17 anos de docência em biologia no mesmo colégio onde aconteceu a pesquisa, além de experiência como secretária de meio ambiente por 3 anos no município de Ipecaetá, Bahia. Ela é formada em Licenciatura em Ciências Biológicas pela Universidade Estadual de Feira de Santana (Uefs), Bahia, e possui Mestrado em Botânica pela mesma universidade. Atualmente é estudante de Doutorado no Programa de Pós-Graduação em Ensino, Filosofia e História das Ciências (PPGEFHC) da Universidade Federal da Bahia (Ufba), em convênio com a Uefs, sendo a primeira autora deste artigo a sua orientadora.

\section{Coleta e Análise dos Dados}

A temática da aula foi Controle Biológico de Insetos e teve o objetivo de identificar e caracterizar os principais insetos causadores de danos à agricultura local e pontuar os organismos vivos que atuam como agentes de controle biológico. Os estudantes foram informados sobre essa temática e objetivo e, após, para identificação dos seus conhecimentos prévios, a professora lançou o seguinte questionamento: - Em suas atividades agrícolas é possível identificar algum organismo que causa danos às plantas que são por vocês cultivadas? - Caso sim, conte-nos o que você sabe sobre ele. A duração total da aula foi de cem minutos, duas horas/aula.

Os estudantes, dispostos em grupos, foram orientados a responder ao questionamento criando narrativas, que poderiam conter palavras escritas e/ou desenhos esquemáticos segundo as suas preferências. Foram cinco grupos compostos por seis estudantes e um grupo formado por cinco. Em cada um desses grupos haviam entre dois e quatro estudantes agricultores. Nosso propósito foi formar grupos com estudantes agricultores e não agricultores a fim de permitir a socialização de saberes culturais, considerando que a escola atende não apenas estudantes agricultores, podendo existir entre eles conhecimentos prévios de natureza científica e/ou das suas comunidades tradicionais agrícolas.

Após as construções das suas narrativas, os estudantes foram convidados a apresentá-las e, nesse momento, foram abertas oportunidades de interações dialógicas entre a professora e os estudantes e entre os estudantes. Os acontecimentos durante toda a aula foram gravados em vídeo e anotados em um diário de campo (CARVALHO, 2006) por uma pesquisadora (primeira autora deste artigo), com o intuito de ajudar nas análises das narrativas e identificação das possibilidades de diálogo intercultural nelas contidas. As análises aconteceram com base nos significados dos conteúdos das narrativas (BARDIN, 2006) e inferências dos autores a partir da literatura científica e anotações no diário de campo. Vale destacar que não é nosso propósito apresentar aqui os episódios das aulas e como nelas aconteceram os processos de ensino e aprendizagem, incluindo aí resultados e discussão; nosso foco são apenas as narrativas e as possibilidades de diálogos nelas identificadas. 


\section{RESULTADOS E DISCUSSÕES}

Cinco grupos apresentaram as suas narrativas unindo a linguagem verbal e a não verbal em livretos contendo escrita e desenhos ilustrativos, e apenas um grupo utilizou a linguagem verbal unicamente, com produção textual em formato de poema escrito.

Dado o curto espaço deste artigo, apresentaremos e discutiremos apenas uma das seis narrativas, que é um dos livretos, selecionado em virtude da sua maior legibilidade e melhor representatividade das ideias com relação aos demais. O livreto escolhido é formado por nove páginas e exibe uma história associada a oito ilustrações. A seguir apresentamos cada uma das páginas que compõem esse livreto, pontuando sobre elas as possibilidades de diálogos com os conteúdos de ensino que foram identificados.

Figura 1 - Páginas 1 e 2 do livreto "Os praguicidas do Zé"
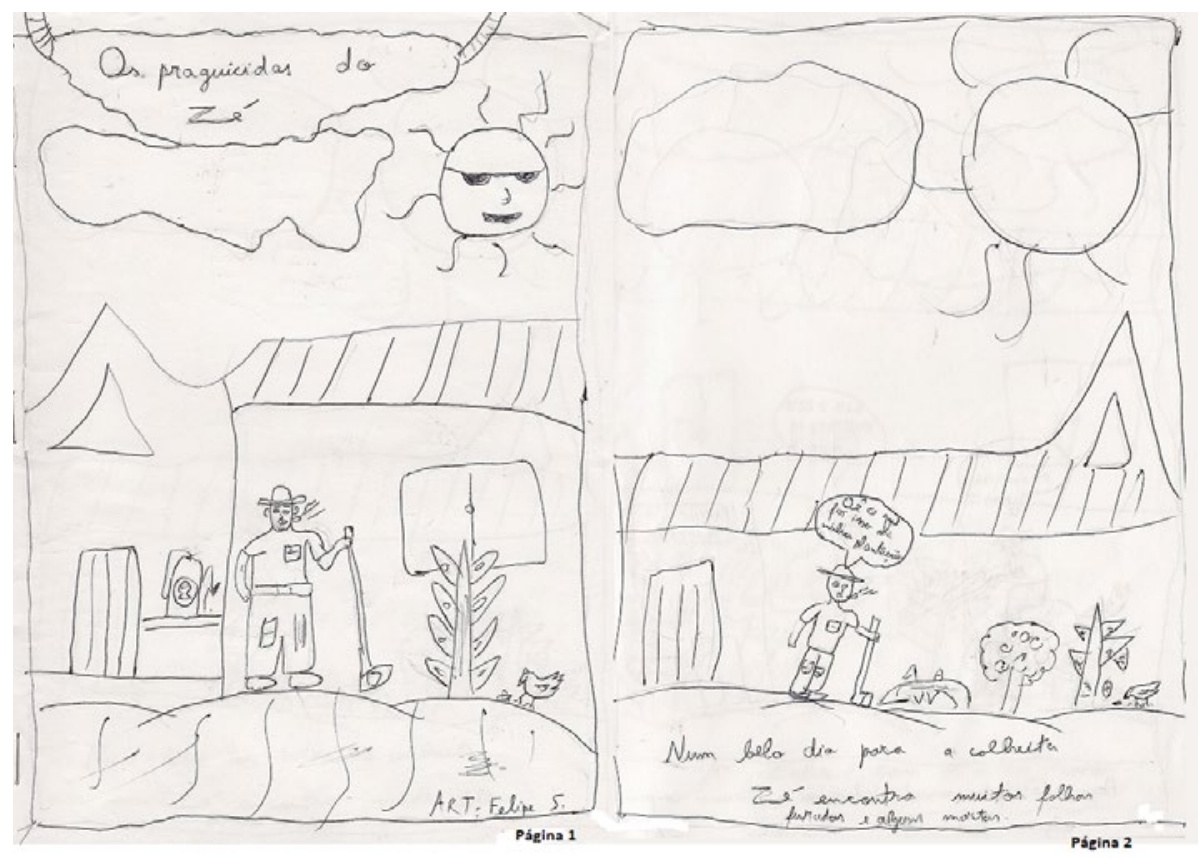

A página 1 da Figura 1 é a capa do livreto contendo o seu título: "Os Praguicidas do Zé". Nela é possível notar que os estudantes reconhecem a existência de relações entre o homem e a natureza. Ela traz uma ilustração representando Zé, que é um agricultor, no seu trabalho de cultivo de milho próximo a uma casa iluminada pelo sol e cercada de vários elementos que compõem o ambiente: solo, água, ar, plantas e animais. Disto, podemos apontar as primeiras possibilidades de diálogo entre os saberes culturais dos estudantes com a biologia: as interações entre o homem e natureza. Ao tratar desta temática, os estudantes poderão compreender como a etnobiologia - estudo do conhecimento e das conceituações desenvolvidas por qualquer sociedade a respeito da biologia (POSEY, 1987) - pode explicar essas interações, partindo de questionamentos como: - Nós, seres humanos, vivemos isolados ou em interdependência com 
os demais elementos da natureza? - Quais seriam as finalidades das interações entre $o$ homem e a natureza? Com estas questões, o professor poderá provocar respostas para a compreensão de que os seres humanos estabelecem amplas ligações com o território habitado por diversas razões e finalidades, que são sempre mediadas por seus meios socioculturais (PEREIRA; DIEGUES, 2010). No caso dos agricultores tradicionais, essas ligações acontecem, frequentemente, em prol do cultivo de plantas úteis para alimentação humana e/ou de animais de criação e, em alguns casos, para pequenos comércios em feiras livres (BRANDEMBURG, 2010).

Na página 2 os estudantes contam que o personagem principal da narrativa vai trabalhar no campo e, ao chegar lá, ele percebe que as plantas cultivadas estão com as folhas devoradas ou mortas e caídas no solo. Aqui, o professor poderá aproveitar a situação para dialogar sobre as interações ecológicas, aspectos morfológicos e fisiológicos das plantas cultivadas, espécies de importância agrícola e entomologia. É importante destacar que os estudantes utilizam o termo "praga" para fazer referência aos insetos de importância agrícola, daí o nosso indicativo de estudo da entomologia nas aulas. As seguintes questões podem abrir o diálogo: - Na natureza, apenas o homem estabelece relações com os demais seres vivos? - Caso não seja, como você percebe essas relações? - Elas são benéficas ou maléficas? Por quê?

De acordo com Maricato e Caldeira (2017), é importante trabalhar com os estudantes as distintas interações entre os seres vivos, elucidando como elas se expressam nos diferentes níveis biológicos de complexidade. Por exemplo, o ontogenético, tratando das origens e desenvolvimento de um organismo desde o embrião até a fase adulta; o filogenético, sobre a relação evolutiva entre grupos de organismos, como entre espécies e populações; o ecológico, sobre como os seres vivos se relacionam entre si e com o meio ambiente, podendo ocorrer não somente entre indivíduos da mesma espécie (relações intraespecíficas), mas também de outras (relações interespecíficas), resultando em benefícios ou não para os envolvidos.

Sobre a abordagem das interações ecológicas, por intermédio do diálogo intercultural os estudantes que são agricultores poderão expor os seus saberes acerca dos insetos que atacam as plantas cultivadas e, a partir daí, o professor apresentar como a biologia explica a morte das folhas encontradas caídas no solo por Zé. Também poderão explicar a nomenclatura científica das espécies de insetos a partir dos nomes tradicionais, apresentando a existência de outros grupos, além dos insetos, que têm importância agrícola, como os fungos e as bactérias. Assim, os estudantes poderão aprofundar os seus saberes com criticidade, compreendendo as relações entre os seus conhecimentos e os conhecimentos científicos. Poderão, ao tratar das relações ecológicas, compreenderem-se como parte integrante da natureza e dela dependentes, capazes de tomar decisões adequadas ante os seus problemas agrícolas, que não promovam o desequilíbrio ambiental e nem influências negativas nas suas vivências nos seus meios socioculturais. 
Figura 2 - Páginas 3 e 4 do livreto "Os praguicidas do Zé"

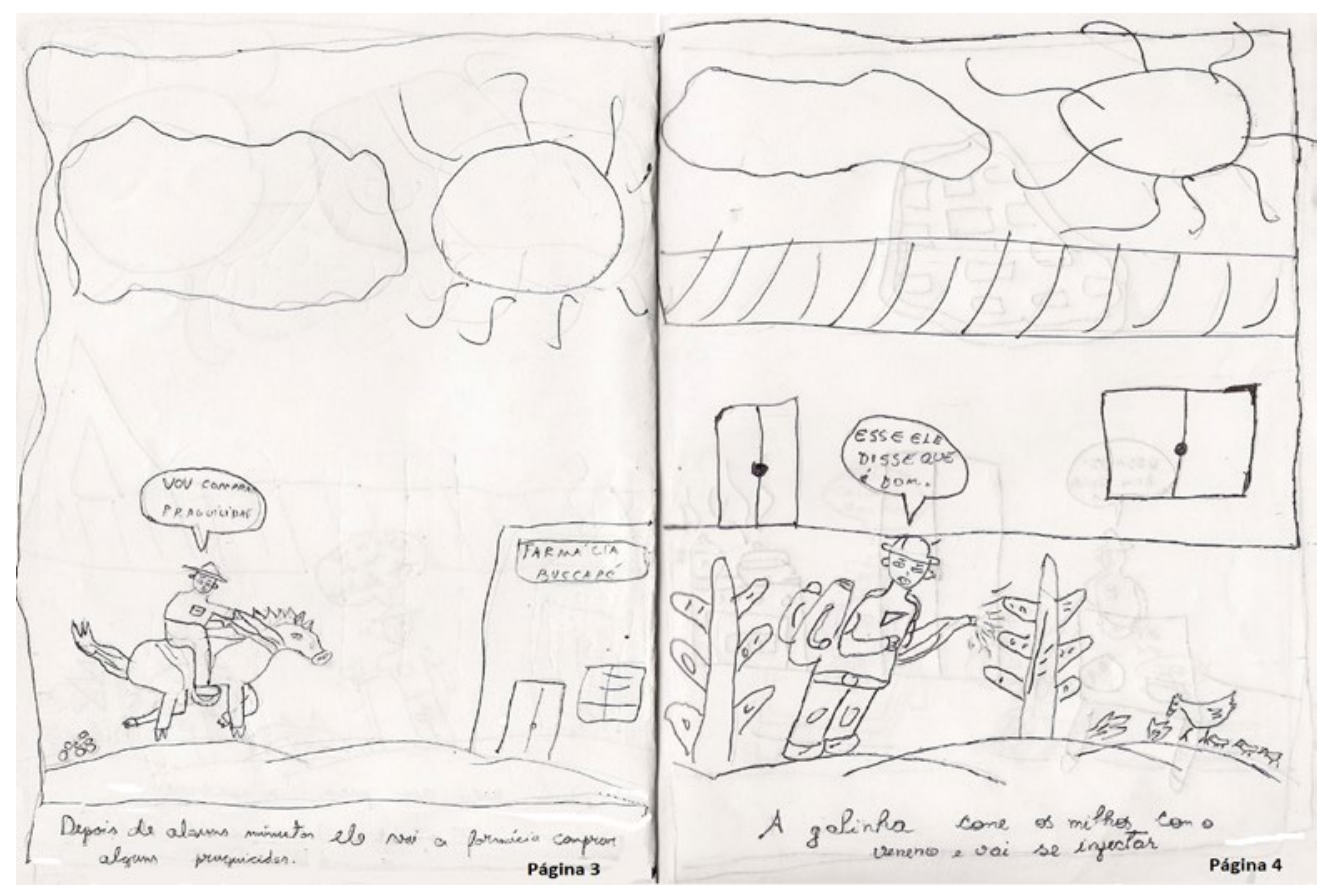

A página 3 nos conta que Zé pegou seu cavalo e foi a uma farmácia (Farmácia Buscapé) para comprar praguicidas (agrotóxicos). Já na página 4, Zé se recorda que o funcionário da farmácia havia lhe dito que o pesticida que lhe foi vendido é bom. Acreditando nisso, ele começa a aplicar o praguicida sobre a plantação de milho com o auxílio de uma bomba acoplada nas suas costas e sem o uso de luvas e máscara. Zé percebe galinhas alimentando-se da vegetação ao redor e declara que elas irão se contaminar comendo o milho que recebeu o praguicida.

Certamente dialogar com os estudantes sobre os agrotóxicos é extremamente importante para a compreensão das dimensões econômicas, sociais, culturais, ambientais, éticas e de saúde ligadas ao seu uso (FERNANDES; STUANI, 2015). Neste contexto, é preciso apresentar o conceito científico de agrotóxico e de contaminação; os métodos que devem ser utilizados para a segurança do agricultor e do meio ambiente; as questões éticas recomendadas pela legislação vigente no país para o uso de defensivos agrícolas; os custos para sua utilização e condições econômicas dos agricultores, entre outros temas que possam surgir.

Sobre as questões ambientais, como é possível notar na narrativa da página 3, os estudantes agricultores reconhecem que o uso de agrotóxicos (praguicidas) atinge outros seres vivos além das plantas, quando ilustram e escrevem que a galinha se alimentando do milho ficará infectada pelo veneno aplicado. Esse reconhecimento abre possibilidade de diálogos sobre a transferência de substâncias químicas na cadeia alimentar, estando de acordo com os achados científicos de, por exemplo, Fernandes e Stuani (2015), que argumentam que os agrotóxicos não atingem somente os produtores, mas, também, os consumidores. O professor poderá motivar as falas dos estudantes com as seguintes questões: - $O$ uso dos agrotóxicos na agricultura pode afetar, além do organismo que ataca a planta, a própria planta, os demais seres vivos e o meio ambiente? Como? Quais as relações existentes entre as plantas cultivadas e a alimentação humana? 
Figura 3 - Páginas 4 e 5 do livreto "Os praguicidas do Zé"

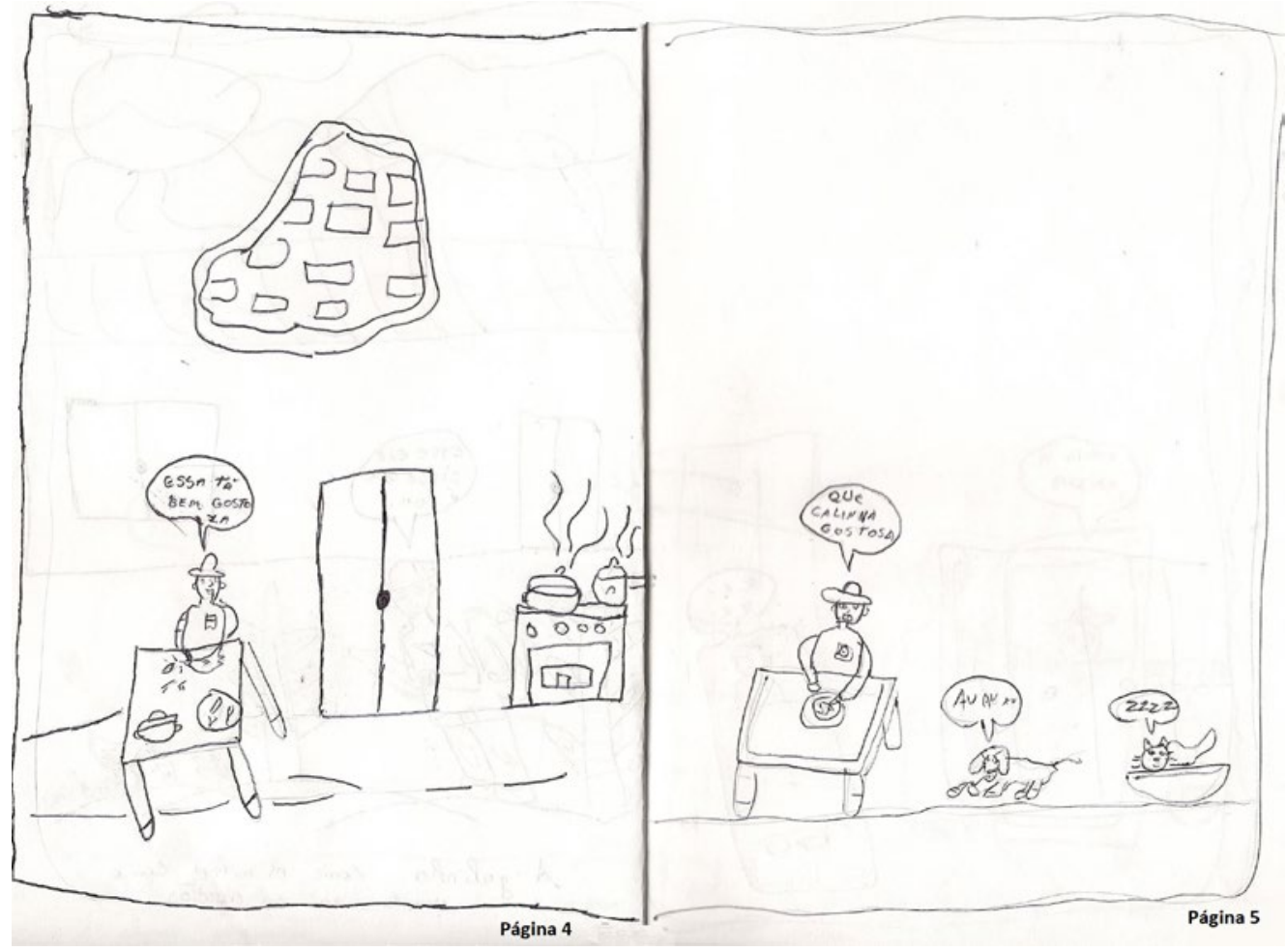

Nas páginas 4 e 5 os estudantes narram que Zé está satisfeito, alimentando-se numa cozinha com a galinha infectada por comer o milho que recebeu o praguicida. Zé também está alimentando um animal de estimação ao seu lado, enquanto outro dorme. Com estas páginas o professor poderá dialogar com os sujeitos a partir de conteúdos científicos relacionados com agrotóxicos, biossegurança, alimentação, higiene e saúde do agricultor, especialmente os riscos de contaminação via oral. Poderá levantar os seguintes questionamentos que abrirão espaços para que os estudantes exponham o que sabem a respeito: - Vocês costumam usar roupas ou equipamentos para se proteger durante a aplicação dos venenos? - Ao chegarem da atividade agrícola vocês costumam lavar as mãos antes das refeições? - Que problemas podem acontecer ao homem ao se alimentar com as mãos sujas ou contaminadas por praguicidas utilizados na agricultura?

As respostas dadas pelos estudantes às questões supra abrirão espaços para que os professores falem sobre as práticas de biossegurança. Isto é, como o uso de Equipamentos de Proteção Individual (EPIs) podem garantir o controle da exposição aos produtos químicos, reduzindo os riscos de intoxicação e promovendo a proteção da saúde dos agricultores (BOHNER; ARAUJO; NISHIJIMA, 2013). A partir disto, o docente poderá argumentar como a falta de uso desses equipamentos pode prejudicar ainda mais a saúde do agricultor, com riscos de intoxicação quando ele não possui hábitos de higiene antes das refeições, pois as mãos contaminadas com agrotóxicos terão contato com os alimentos que serão ingeridos. Hábitos como tomar banho, trocar as roupas utilizadas no trabalho agrícola por roupas limpas e lavar as mãos, certamente contribuirão para minimizar os riscos de contaminação dos alimentos durante as refeições. 
Figura 4 - Páginas 6 e 7 do livreto "Os praguicidas do Zé"

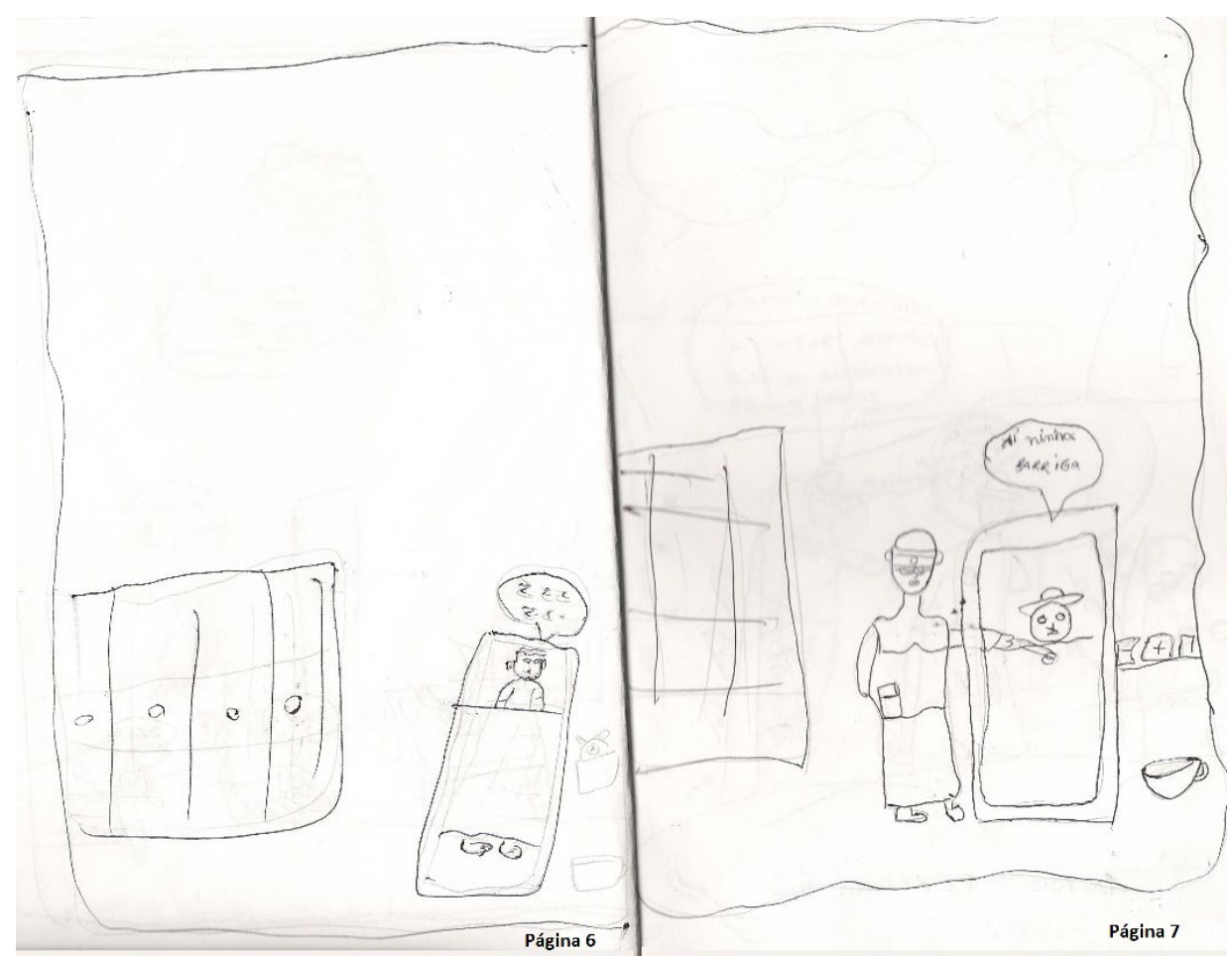

Nas páginas 6 e 7 Zé foi acamado por estar doente logo após ter se alimentado da galinha contaminada com o veneno aplicado sobre o milho. Então, ele chama um médico a sua casa para examiná-lo, pois apresentava fortes dores na barriga (diarreia). Aqui é possível dialogar com os estudantes conteúdos como doenças causadas por contaminação de alimentos e efeitos cumulativos de substâncias (Bioacumulação). O professor poderá partir de questionamentos como: - Será que as plantas que receberam pesticidas e que servem de alimento para os seres vivos podem interferir na saúde humana? Como? - Como os venenos aplicados nas plantas podem chegar ao organismo humano? - Quais as doenças mais comuns que atingem os agricultores e por que elas acontecem?

Para Fernandes e Stuani (2015), os agrotóxicos, ao atingirem a cadeia alimentar, causam malefícios ao homem, tanto do campo quanto dos meios urbanos, que se alimentam de produtos contaminados. Isto acontece por conta da bioacumulação, isto é, um processo que ocorre quando uma substância química se acumula em elevadas concentrações nos organismos em níveis tróficos (os produtores, os consumidores e os decompositores). Quando Zé se alimentou da galinha contaminada com o agrotóxico, ele também foi contaminado, apresentando problemas no aparelho digestório. Um estudo realizado por Stopelli, (2005) com agricultores do Estado de São Paulo, revela que as doenças mais comuns entre os trabalhadores da agricultura, que são resultantes do uso de agrotóxicos, são as neoplasias de pele e do sistema digestório. Sendo assim, abordagens dialógicas neste sentido ampliarão os saberes dos estudantes, contribuindo para que minimizem o uso dos agrotóxicos ou mesmo evite-os com recursos alternativos. 
Figura 5 - Páginas 8 e 9 do livreto "Os praguicidas do Zé"

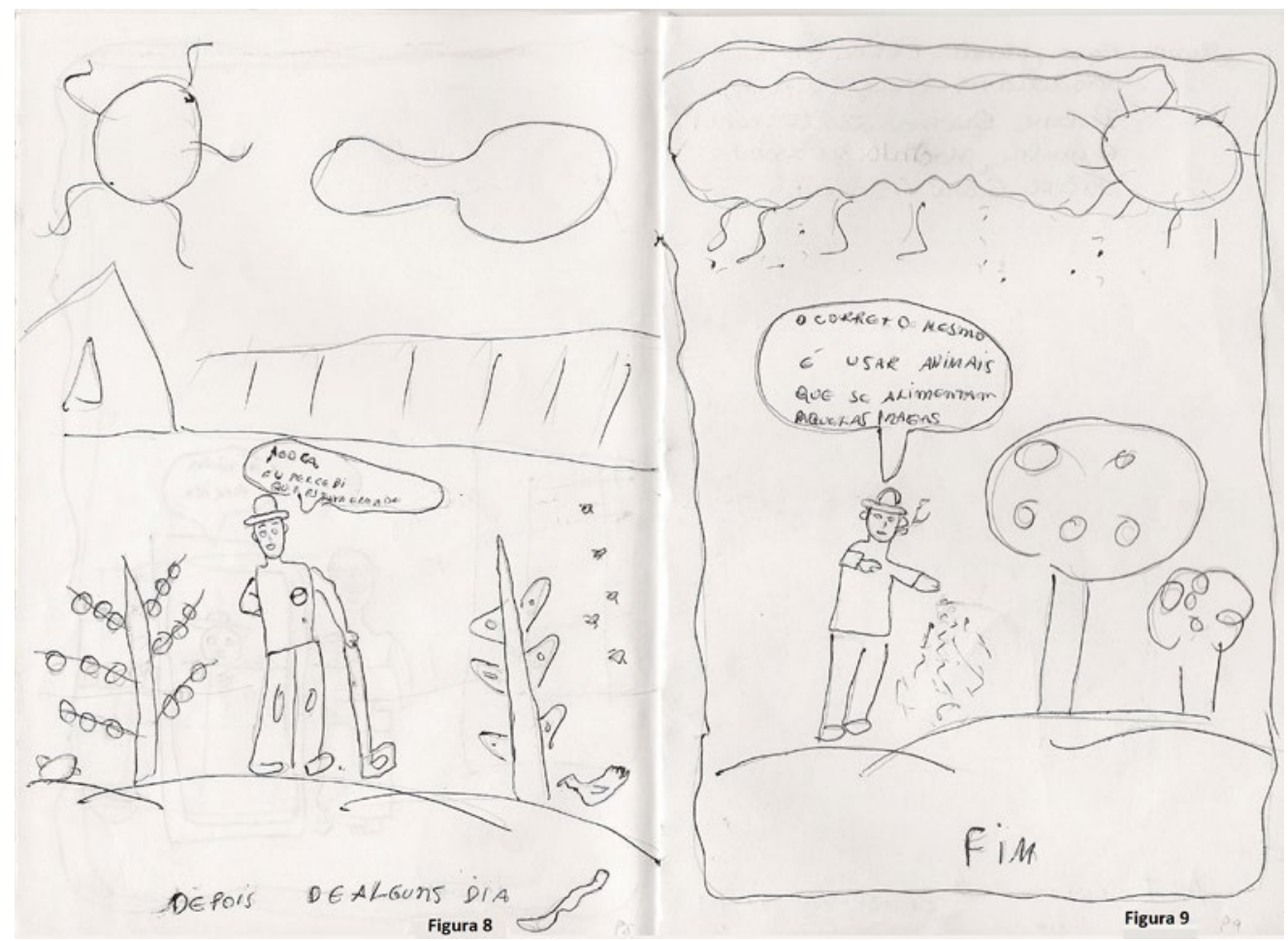

Nas páginas 8 e 9 da narrativa, Zé, tendo melhorado do seu problema de saúde e voltado ao trabalho no campo, fica pensativo e exclama: "Agora eu percebi que estava errado". E continua seu pensamento com a afirmativa de que "o correto mesmo é usar animais que se alimentam daquelas pragas". Aqui, o professor poderá dialogar apresentando aos estudantes conteúdos ligados ao controle biológico de pragas agrícolas. Para isto, poderá partir dos seguintes questionamentos: - Será que somente os praguicidas que vocês utilizam podem combater as pragas agrícolas? - Na comunidade agrícola de vocês, os seus pais e/ou antepassados fazem ou já fizeram uso de algum ser vivo para combater as pragas? Quais?

Segundo Grigoletti-Júnior (2000), controle biológico é o controle de um organismo por outro organismo. Segundo Parra et al. (2002), o controle biológico é um fenômeno dinâmico que, por meio da liberação, incremento e conservação de inimigos naturais (parasitoides, predadores e microrganismos), impede que os insetos causem danos às plantações e, ao mesmo tempo, contribuem para a qualidade ambiental por não deixar resíduos tóxicos no ambiente, como frequentemente acontece com o uso dos agrotóxicos.

No caso da realidade agrícola dos estudantes que participaram do nosso estudo, a necessidade de controle biológico está sobre organismos que atacam a plantação do milho, possivelmente a lagarta-do-cartucho (Spodoptera frugiperda), uma espécie de inseto muito comum no Brasil, que, na fase de lagarta, ataca as folhas até sua completa destruição (BERNARDI et al., 2015). Além de dialogar sobre a nomenclatura científica e a tradicional, os professores podem explicar que existem alternativas aos agrotóxicos para o controle dessa espécie, como a tesourinha (Doru luteipes $s p$.), um inseto predador tanto dos ovos quanto das lagartas pequenas. 
Assim, dados os efeitos negativos sobre o meio ambiente e os seres vivos a partir do uso dos agrotóxicos, torna-se imperativo diálogos com os agricultores que visem o desenvolvimento de sistemas de cultivo menos dependentes do uso dessas substâncias. Neste sentido, o controle biológico constitui um conteúdo central para o ensino de ciências em comunidades tradicionais agrícolas, e mesmo em escolas localizadas em comunidades urbanas que atendam estudantes agricultores. Isto porque pode contribuir para uma agricultura sustentável que envolva o manejo adequado das plantas cultivadas e demais elementos da natureza a elas associados, evitando a degradação ambiental sem, contudo, impedir as ações humanas resultantes das suas necessidades, sejam elas de vivências e/ou culturais, tanto das gerações atuais quanto futuras.

\section{CONSIDERAÇÕES FINAIS}

O objetivo da nossa pesquisa foi identificar as possibilidades de diálogo intercultural na educação científica em biologia a partir de narrativas feitas por estudantes pertencentes às comunidades tradicionais em linguagem verbal e não verbal, particularmente estudantes agricultores que frequentavam em 2009 um colégio público do Estado da Bahia, localizado no município de Feira de Santana.

Nossas análises sobre as narrativas criadas por esses estudantes indicam uma combinação das linguagens verbal e não verbal, sendo esta última a predominante, pois apresentou mais desenhos em relação a palavras. Isto significa que a linguagem não verbal foi mais instintiva para os estudantes do que a linguagem verbal, por não envolver palavras, as quais necessitam de regras gramaticais e ortográficas para serem compreendidas. Em casos como este, sugerimos aos professores mais atenção e motivação das participações dos estudantes, para que consigam decodificar aquilo que eles estão representando nas suas narrativas, o que certamente poderá ser alcançado via diálogos interculturais.

As análises também permitiram identificar ricas possibilidade de diálogos entre os conhecimentos tradicionais agrícolas e os científico-escolares, podendo partir de inúmeros questionamentos acerca de conteúdos de ensino, tais como: interações dos seres humanos com os demais seres vivos; relações ecológicas; aspectos morfológicos dos vegetais; insetos de importância agrícola; o uso de agrotóxicos, seus benefícios e malefícios; envenenamento e saúde dos agricultores; bioacumulação; higiene e alimentação; e controle biológico de pragas agrícolas. Cada um desses conteúdos, quando envolvidos no diálogo intercultural, poderá contribuir fortemente para a ampliação dos saberes e práticas culturais dos estudantes, não apenas dos agricultores, mas, também, dos não agricultores que estiveram envolvidos nas construções das narrativas.

Assim, consideramos que atividades didáticas envolvendo narrativas dos estudantes podem facilitar a representação dos seus saberes culturais na realização da prática pedagógica baseada no diálogo entre a cultura científica e as culturas dos estudantes. Por conseguinte, podem contribuir para a formação docente neste sentido, tornando o professor sensível à diversidade cultural presente nas salas de aula, com respeito e consideração nos momentos de ensino.

Pretendemos dar continuidade ao nosso estudo no sentido de avaliar como o diálogo intercultural, estabelecido nas aulas de ciências a partir de narrativas construídas por estudantes agricultores, pode contribuir para as tomadas de decisão ante os problemas agrícolas por eles vivenciados. 


\section{REFERÊNCIAS}

BAPTISTA, G. C. S. Importância da demarcação de saberes no ensino de Ciências para sociedades tradicionais. Ciência \& Educação, v. 16, n. 3, 2010, p. 679-694.

BAPTISTA, G. C. S. A etnobiologia e sua importância para a formação do professor de ciências sensível à diversidade cultural: indícios de mudanças das concepções de professoras de biologia do estado da Bahia. 2012. 404 f. Tese (Doutorado em Ensino, Filosofia e História das Ciências) - UFBA-UEFS, Salvador, 2012.

BARDIN, L. Análise de conteúdo. Lisboa: Edições 70, 2006.

BERNARDI, O.; BERNARDI, D.; RIBEIRO, R. S.; OKUMA, D. M.; SALMERON, E.; FATORETTO, J.; MEDEIROS, F. C. L.; BURD, T.; OMOTO, C. Frequency of resistance to Vip3Aa20 toxin from Bacillus thuringiensis in Spodoptera frugiperda (Lepidoptera: Noctuidae) populations in Brazil. Crop Protection v. 76, p. 7-14, 2015.

BOGDAN, R.C.; BIKLEN, S. K. Investigação qualitativa em educação. Tradução Maria João Alvarez, Sara Bahia dos Santos e Telmo Mourinho Baptista. Porto: Porto Editora, 1994.

BOHNER, T. O. L.; ARAUJO, L. E. B.; NISHIJIMA, T. A biossegurança no uso de defensivos agrícolas na percepção dos agricultores do município de Chapecó, SC. Revista Eletrônica do curso de direito da UFSM, v. 8, p. 690-699, 2013.

BRANDEMBURG, A. Do rural tradicional ao rural socioambiental. Ambiente \& Sociedade, v. XIII, n. 2, p. 417-428, 2010.

BRASIL. Conselho Nacional de Saúde. Comissão Nacional de Ética em Pesquisa. Normas para pesquisa envolvendo seres humanos. Resolução 196/96. 2. ed. Brasília: Ministério da Saúde, 2003.

CARTER, K. The place of story in the study of teaching and teacher education. Educational Researcher, Washington, v. 22, n. 1, p. 5-12, 1993.

CAPPELLE, V.; MUNFORD, D. Desenhando e escrevendo para aprender ciências nos Anos Iniciais do Ensino Fundamental. Alexandria - Revista de Educação em Ciência e Tecnologia, v. 8, n. 2, p. 123-142, jun. 2015. CARVALHO, A. M. P. Uma metodologia de pesquisa para estudar os processos de ensino e aprendizagem em salas de aula. In: SANTOS, F. M. T. dos; GRECA, I. M. (org.). A pesquisa em ensino de ciências no Brasil e suas metodologias. Ijuí: Ed. Unijuí, 2006. p. 13-48.

CONNELLY, M.; CLANDININ, J. Stories of Experience and Narrative Inquiry. Educational Researcher, Washington, v. 19, n. 5, p. 2-14, 1990.

DIEGUES, A. C. S.; ARRUDA, R. S. V. Saberes tradicionais e biodiversidade no Brasil. Biodiversidade 4. Ministério do Meio Ambiente. Brasília; São Paulo: Nupaub; USP, 2001.

FERNANDES, C. dos S.; STUANI, G. M. Agrotóxicos no Ensino de Ciências: uma pesquisa na educação do campo. Educação \& Realidade, v. 40, n. 3, p. 745-762, 2015.

GHEDINI, C. M. Educação popular e referências formativas: elos que enraízam o projeto educativo da educação do campo no Brasil. Revista Contexto \& Educação, ano 32, n. 101, jan./abr. 2017.

GRIGOLETTI-JUNIOR, A.; SANTOS, A. F. dos; AUER, C. G. Perspectivas do uso do controle biológico contra doenças florestais. Floresta, v. 30, n. 1/2, p. 155-165, 2000.

MARICATO, F. E.; CALDEIRA, A. M. de. O conceito de interação biológica/ecológica: contribuição aos estudos em epistemologia da biologia e ao ensino de biologia. Acta Scientiarum Education, v. 39, n. 4, p. 441-451, 2017. MORTIMER, E. F. Construtivismo, mudança conceitual e ensino de ciências: para onde vamos? Investigações em Ensino de Ciências, Porto Alegre, v. 1, n. 1, p. 20-39, 1996. Disponível em: http://www.if.ufrgs. br/ienci/artigos/Artigo_ID8/v1_n1_a2.pdf. Acesso em: 27 abr. 2005.

OSBORNE, J.; ERDURAN, S.; SIMON, S.; MONKIN, M. Enhancing the quality of argument in school science. School Science Review, v. 82, n. 301, p. 63-70, 2001.

PARRA, J. R.; BOTELHO, P. S. M.; CORRÊA-FERREIRA, B. S.; BENTO, J. M. S. Controle biológico no Brasil: terminologia. In: PARRA, J. R. P.; BOTELHO, P. S. M.; COORÊA-FERREIRA, B. S.; BENTO, J. M. S. (eds.). Controle biológico no Brasil: parasitóides e predadores. São Paulo: Ed. Manole, 2002. 609 p.

PEREIRA, B. E.; DIEGUES, A. C. Conhecimento de populações tradicionais como possibilidade de conservação da natureza: uma reflexão sobre a perspectiva da etnoconservação. Desenvolvimento e Meio ambiente, n. 22, p. 37-50, 2010.

POSEY, D. A. Introdução - etnobiologia: teoria e prática. In: RIBEIRO, D. (ed.). Suma etnológica brasileira. Petrópolis: Vozes; Finep. p. 15-25, 1987. V. 1.

POSNER, G. J., STRIKE, K. A., HEWSON, P. W.; GERTZOG, W. A. Accomodation of a scientific conception: toward a theory of conceptual change. Science Education, v. 66, n. 22, 1982, p. 211-227.

STOPELLI, I. M. de B. S. Agricultura, ambiente e saúde: uma abordagem sobre o risco do contato com os agrotóxicos a partir de um registro hospitalar de referência regional. 2005, 155p. Tese (Doutorado) - Escola de Engenharia de São Carlos, Programa de Pós-Graduação em Ciências da Engenharia Ambiental, São Carlos, São Paulo, 2005.

VYGOTSKY, L. S. Pensamento e linguagem. 3. ed. São Paulo: Martins Fontes, 1991. 